\title{
Discovery and conservation of the $\mathrm{Vu}$ Quang ox in Vietnam
}

\author{
Vu Van Dung, Pham Mong Giao, Nguyen Ngoc Chinh, Do Tuoc \\ and John MacKinnon
}

In May 1992 the discovery of three pairs of horns in the only remaining area of pristine forest in northern Vietnam led to the description of a new species of ox. A total of 20 specimens have now been found, most of them consisting of only the horns and part of the skull. The Ministry of

Forestry in Vietnam is enlarging and upgrading protected areas in the suspected 4000-sq-km range of the Vu Quang ox and surveys are under way in two proposed reserves in neighbouring Laos where the ox is also reported to occur. Meanwhile a local campaign is necessary to inform villagers of the valuable nature of this species and to ban further hunting.

\section{Discovery of a new bovid}

In May 1992 a joint expedition by the Ministry of Forestry (MOF) and World Wide Fund for Nature (WWF) made surveys of the Vu Quang Nature Reserve in $\mathrm{Ha}$ Tinh province of Vietnam (MacKinnon and Dung, 1992). The team had expected and found the serow Capricornis sumatraensis but also found three sets of horns of a second bovid in hunters' houses. This species had long, almost straight horns and was immediately recognized to be something new. One specimen was so fresh that it still had maggots on it. Unfortunately none of the specimens had dentition. The specimens were photographed, measured and one was taken to the Forest Inventory and Planning Institute (FIPI) of the Ministry of Forestry (MOF) in Hanoi. The WWF announced the news that a new species of large mammal had been discovered. A sample of skin and hair was sent to the United States for DNA analysis.

Several follow-up visits have been made to the area and reports of the same animal have come in from a wider area. Four visits to $\mathrm{Vu}$ Quang revealed more specimens and surveys of nearby forests in Nghe An province revealed more localities and partial specimens.

A total of over 20 specimens have been lo- cated and examined by the authors. Most of these consist only of horns having been cut off through the cranium to nasals. Four specimens have the complete upper mandible and upper teeth and three sets have lower mandibles and teeth. Many of the specimens have skin on the frontal area. Three specimens have a complete skin with feet. One of these has now been stuffed and mounted.

\section{Distribution}

Definite records are now known from over 20 localities, all on the forest edge along the pristine forest cordillera along the Lao/Vietnam border between $104^{\circ} 5^{\prime} \mathrm{E}, 19^{\circ} 25^{\prime} \mathrm{N}$ and $105^{\circ} 50^{\prime}$, $18^{\circ} 05^{\prime} \mathrm{N}$. All specimens are from the Vietnam (wetter) side of the range, but hunters report that the animal does also exist on the Lao side. All definite records are to the south of the Song $\mathrm{Ca}$ River. Figure 1 shows the distribution of the species as currently known. This indicates a total range of about $4000 \mathrm{sq} \mathrm{km}$.

\section{Description of habitat}

The border area where the new bovid is found constitutes the only extensive pristine forest in 
Figure 1. Distribution map of new bovid.

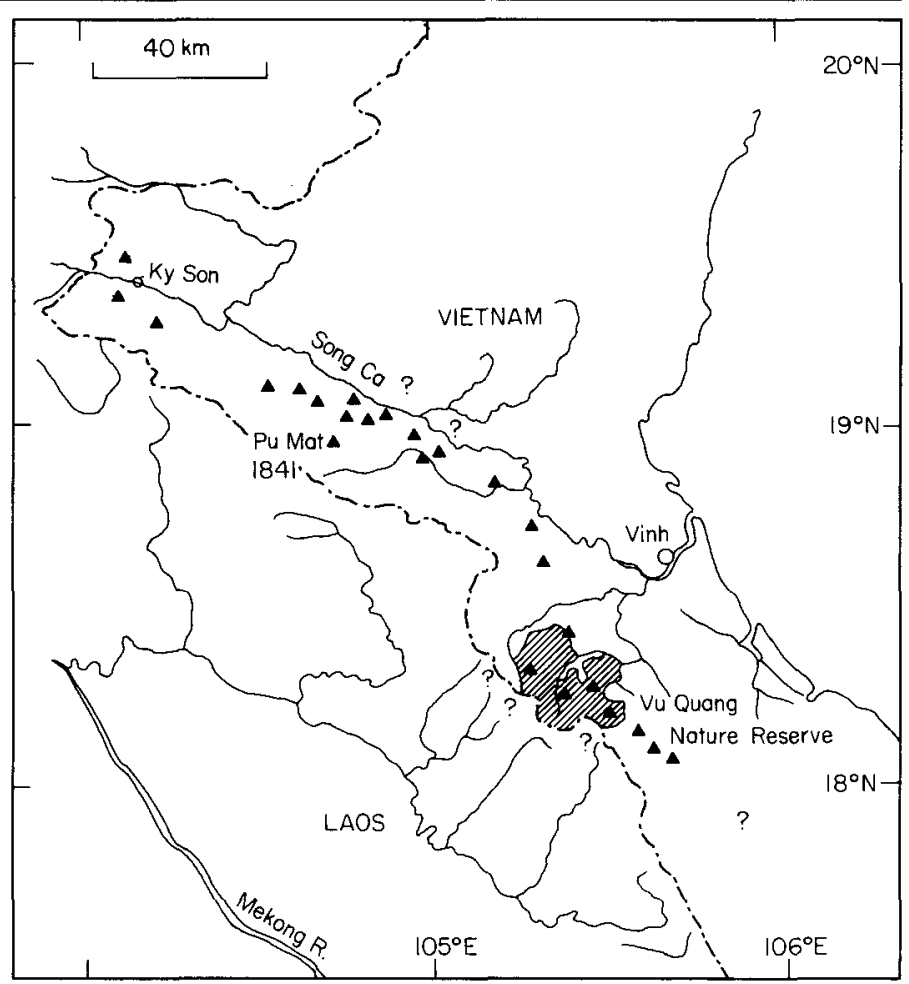

northern Vietnam. The montane forests are dominated by conifers with Fokenia hodgsoni being the main species. Lower forests are rich, evergreen mixed broad-leaf dominated by the dipterocarp Hopea mollissima. The new bovid appears to use all forest levels in different seasons, even entering the secondary lowland forests along large rivers at about $200 \mathrm{~m}$. Highest peaks in the range are over $2000 \mathrm{~m}$ above sea-level.

\section{General description}

The total adult body weight is estimated at about $100 \mathrm{~kg}$. The total length from nose to anus is between 1.5 and $2 \mathrm{~m}$ and height at the shoulder is about $0.9 \mathrm{~m}$. The length from spine to fore foot across preserved skin was $0.96 \mathrm{~m}$. The tail is short, with about $130 \mathrm{~mm}$ of bone, as are the ears, at about $100 \mathrm{~mm}$.

The horns are the most striking feature, being very long, almost straight and very sharp (Figure 2). The bone extends almost to the tip of the horn sheath. Both the length and distance between the tips show a bimodal distribution with inferred males having longer, more divergent horns than females. The horns are peculiar in being almost circular in crosssection and lacking a keel ridge. There are narrow annuli on the basal $70 \mathrm{~mm}$ but the main shaft is rubbed smooth. The angle of the horns is so swept back that the horns rest on the back of the animal if it raises its head.

The species is strikingly coloured rich brown with bold markings of black and white (Figure 2). The face and general body colour varies from dark brown to rich reddish brown. There is a blackish brown narrow stripe down the middle of the back on to the short tail, which has a black fluffy tip. Both sexes have whitish to buff stripes above and below the eye and white patterns on the side of the face, chin and throat. One specimen (inferred female) has whitish patches on the side of the neck. Both complete skins show a whitish stripe on the outer flanks separating the brown back from blackish legs. Both skins 
Table 1. The main morphological characters of the Vu Quang ox compared with other Asian bovids

\begin{tabular}{lcccccc}
\hline Character & Anoa & Cattle & Serow & Goral & Nilgai & Oryx \\
\hline Medium size & + & - & + & - & + & + \\
Short fluffy tail & - & - & + & + & - & - \\
Smallish ears & + & - & - & + & + & - \\
Straight horns & + & - & - & - & + & + \\
Horns long & - & + & - & - & - & + \\
No horn ridge keel & - & + & + & + & - & + \\
Little corrugation & + & - & - & - & + & - \\
Wide horn insertion & + & + & - & - & + & + \\
B/W face stripes & - & - & - & - & + & + \\
White socklets & - & + & - & - & + & + \\
Dark dorsal stripe & - & - & + & + & + & + \\
Neck patch & + & - & - & + & + & - \\
Rump patch & - & + & - & - & - & + \\
Lack of mane & + & + & - & - & + & + \\
Face gland & - & - & + & + & + & - \\
Degree of similarity & 7 & 6 & 6 & 6 & 10 & 9 \\
\hline
\end{tabular}

(one of each sex) show whitish socklet markings with a black frontal division (Figure 3). The hair on the upperparts is short (about 24 $\mathrm{mm}$ ) and glossy while that on the underparts is longer $(35 \mathrm{~mm})$ and fluffier. The hair is fine in contrast to the coarse hair of goat-antelopes. The anal area and inner flanks are whitish as is the scrotum of the male skin. The ear is brown behind and whitish inside with short hair except for a tuft of long whitish hair on the upper innerside of the ear. The hair pattern results in whorls on the centre of the nose, sides of neck, and middle of shoulders. The animal has no crest of long hair as in goatantelopes and nilgai.

The hooves are short and blunt, with toes about $40 \mathrm{~mm}$ deep and $60 \mathrm{~mm}$ long. The 'dew toes' are vestigial callouses, much more reduced than in goat-antelopes or cattle (Figure 3 )

There are glands just in front of the eye as in goat-antelopes. In both complete skins and some other specimens these have been cut out by villagers, presumably for use as medicine.

\section{Comparison with other bovids}

Table 1 indicates how the main characters of the new bovid compare with other genera of Asian bovids. (Oryx occurred in India in
Pliocene-Pleistocene). The new bovid differs significantly from all known genera, but shows more superficial resemblance to the nilgai than to other bovids. The results of the DNA analysis confirm the species to be a deep branch of the subfamily bovinae and the name Pseudoryx nghetinhensis has been given to the species (Dung et al., 1993).

\section{Behaviour}

The animal is occasionally caught in snares set for deer and sometimes shot by hunters using dogs or torchlighting. It reportedly keeps to the high hills in the summer months when upper streams have plenty of water but comes down into the lowlands in winter when the upper streams become dry. Almost all hunted specimens are obtained in winter.

The animals is said to travel in small groups of 2-3 animals, rarely up to $6-7$ animals. They are very shy and never enter agricultural lands.

All horns show heavy wear on both anterior and posterior surfaces indicating that they are regularly sharpened by rubbing on small trees. The extension of the bone to almost the tip of the horns indicates they serve a real fighting role, maybe in defence against predators. Both tiger and leopard occur in the region. 


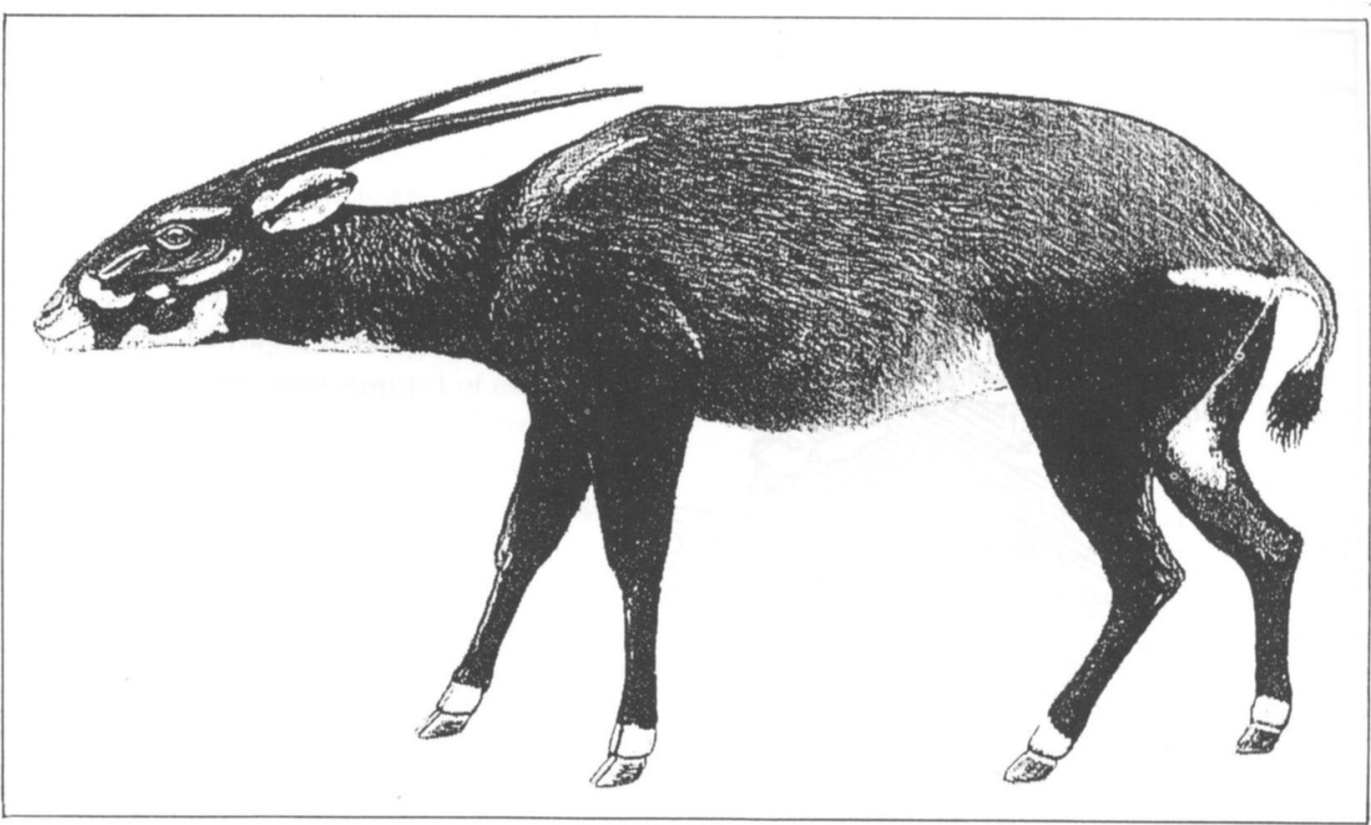

Figure 2. Portrait of Vu Quang ox.

Villagers say that the ox eats the leaves of fig trees and other bushes along riverbanks and is particularly fond of the medicinal herb Homalomena aromatica (Araceae). The small size of the incisors suggests a browsing diet.

\section{Local names}

The local name in Nghe An province is Sao La, which means 'spindle' horn, referring to the similarity between the long pointed horns and local weaving spindles. The local name in $\mathrm{Ha}$ Tinh province is Son Duong, which means mountain goat. The serow, which lives in the same area, is called Xe Rung, which means goat of the forest goat.

\section{Conservation of new bovid}

Immediately after the discovery of the new bovid, the Ministry of Forestry decided to enlarge the Vu Quang Nature Reserve and cancel logging in the $\mathrm{Vu}$ Quang enterprise. The reserve has now been enlarged to 60,000 ha with an additional buffer zone of 15,000 ha. A draft management plan for the area was prepared by MoF/WWF (MacKinnon and Dung, 1992). The Dutch Government is now designing a project to help the government protect and develop the area as a national park with WWF assistance.

In addition, a large area of primary forest remaining south of Song Ca River in Nghe an
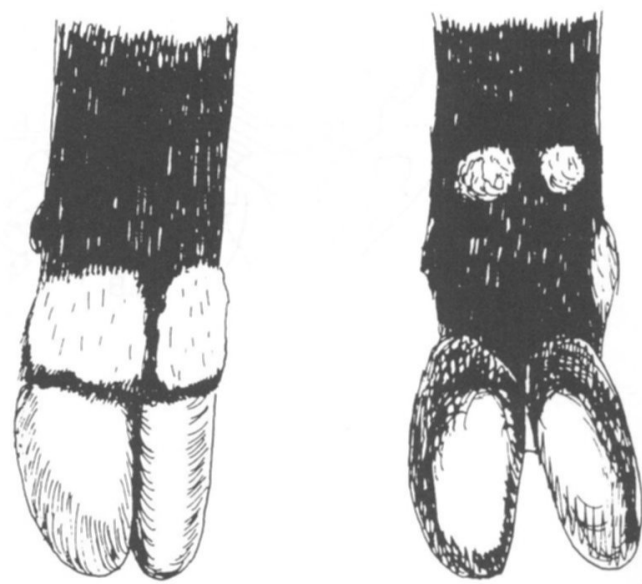

Figure 3. Front forefoot of Vu Quang ox, showing white socklets and very reduced 'dew toes'. 


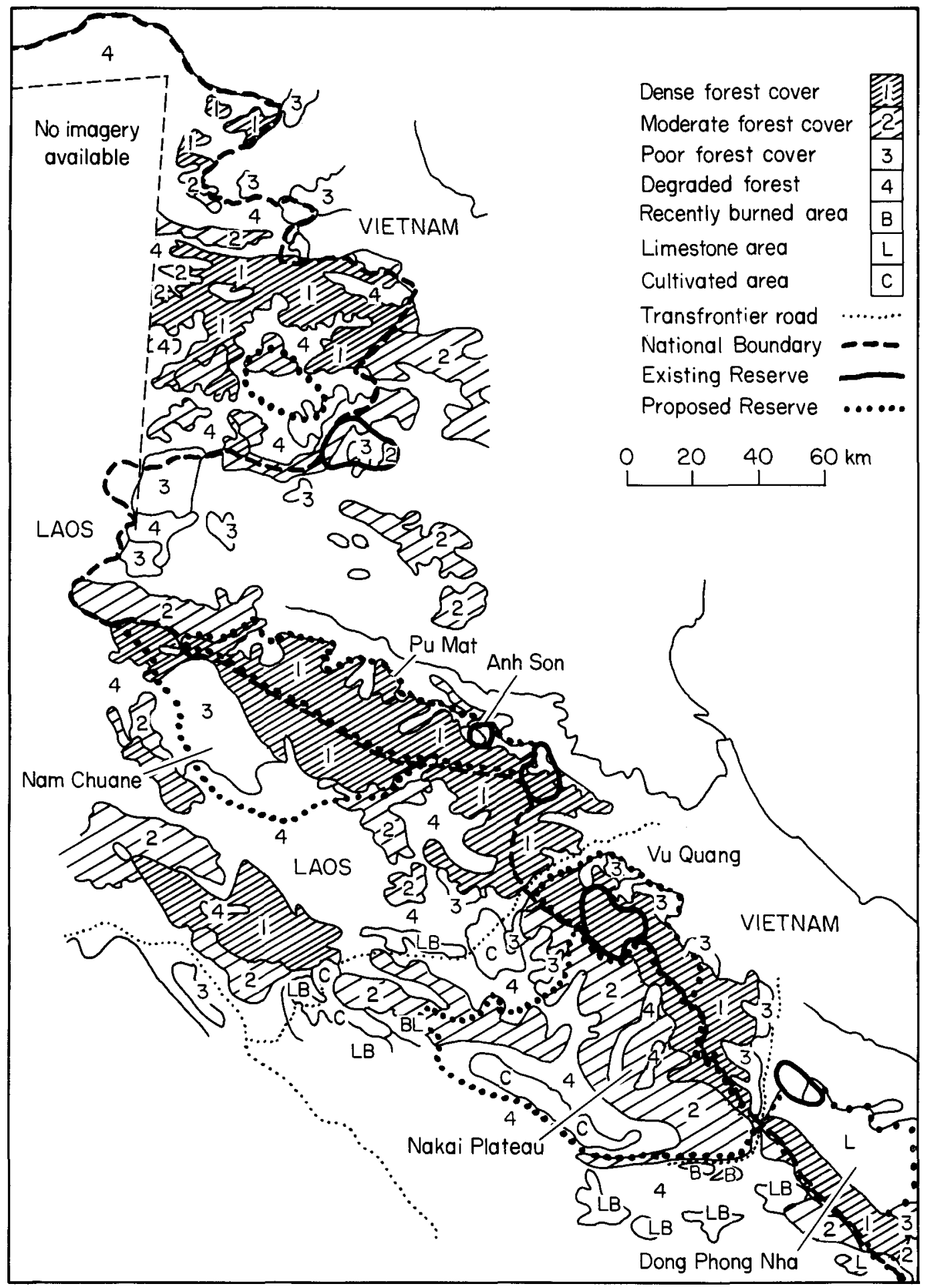

Figure 4. Map showing forest condition, existing and proposed reserves in distribution of Vu Quang ox. 
province is currently being surveyed by FIPI with a view to making it a nature reserve. The area is referred to as $\mathrm{Pu}$ Mat after the highest peak in the area $(1841 \mathrm{~m})$.

Two large proposed reserves on the Lao side of the border will be surveyed by teams of the Department of Wildlife and IUCN (Salter et al., 1991). A United Nations Development Programme regional project will focus on the area in the context of establishing transfrontier reserves. Figure 4 shows the distribution of forest cover and the location of existing and proposed reserves in the range of the species.

It is important to inform local villagers of the precious nature of this species and put a firm ban on further hunting. The rush to acquire specimens of the new species must be stemmed and firm penalties demonstrated for poaching.

The species is to be given protected status and special measures designed to conserve it. It is already planned to have the species listed on Appendix $I$ to the Convention on International Trade in Endangered Species of Fauna and Flora (CITES) even though Vietnam is still not a Party to the Convention. Funds are being sought to mount a full survey and study of the animal and its habitat. It is currently not possible to estimate the numbers of the animal but, because over 20 example have been found in a relatively short period, we believe there must be several hundred left in the wild.

\section{Acknowledgments}

We would like to thank WWF for sponsoring the expedition that led to this valuable discovery and the local government of $\mathrm{Ha}$ Tinh province for its permission and logistical support for the surveys and extension of Vu Quang Nature Reserve.

\section{References}

Boonsong Lekagul and McNeely, J.A.. 1977. Mammals of Thailand. Association for the Conservation of Wildlife, Bangkok.

Dung, V.V., Giao, P.M., Chinh, N.N., Do Tuoc. Arctander, P. and MacKinnon, J. 1993. Discovery of a new bovid from Vietnam, Nature, 363, 443-445.

MacKinnon, J and Dung, V.V. 1992. Draft Management Plan for $V u$ Quang Nature Reserve, Huong Khe District, Ha Tinh Province, Vietnam. Report of MoF/WWF.

Salter, R.E., Bouaphanh Phanthavong and Venevongphet. 1991. Planning and Development of a Protected Area System in Lao PDR: Status Report to Mid-1991. Forestry Resources Conservation Project, Lao/Swedish Cooperative Programme, Vientiane.

Vu Van Dung, FIPI, Hanoi, Vietnam.

Pham Mong Giao, MOF, Hanoi, Vietnam.

Nguyen Ngoc Chinh, FIPI, Hanoi, Vietnam.

Do Tuoc, FIPI, Hanoi, Vietnam.

John MacKinnon, Asian Bureau for Conservation, 18E Capital Building, 175-191 Lockhart Road, Wanchai, Hong Kong. 